A.S. Kuznetsov, M. A. Gleeson and F. Bijkerk (2014). "Temperature dependencies of hydrogen-induced blistering of thin film multilayers." Journal of Applied Physics 115(17): 173510.

DOI: $10.1063 / 1.4875484$

\title{
Temperature dependencies of hydrogen-induced blistering of thin film multilayers
}

\author{
A.S. Kuznetsov ${ }^{1}$, M.A. Gleeson ${ }^{1,1}$ and F.Bijkerk ${ }^{1,2}$ \\ ${ }^{1}$ DIFFER - Dutch Institute for Fundamental Energy Research, Postbus 1207, 3430 BE Nieuwegein, The \\ Netherlands. \\ ${ }^{2} \mathrm{MESA}^{+}$Institute for Nanotechnology, University of Twente, Postbus 217, 7500 AE Enschede, The \\ Netherlands.
}

\begin{abstract}
We report on the influence of sample temperature on the development of hydrogen-induced

blisters in Mo/Si thin-film multilayers. In general, the areal number density of blisters decreases with increasing exposure temperature, whereas individual blister size increases with exposure temperatures up to $\sim 200{ }^{\circ} \mathrm{C}$ but decreases thereafter. Comparison as a function of sample temperature is made between exposures to a flux containing both hydrogen ions and neutrals and one containing only neutrals. In the case of the neutral-only flux, blistering is observed for exposure temperatures $\geq 90{ }^{\circ} \mathrm{C}$. The inclusion of ions promotes blister formation at $<90{ }^{\circ} \mathrm{C}$, while retarding their growth at higher temperatures. In general, ioninduced effects become less evident with increasing exposure temperature. At $200{ }^{\circ} \mathrm{C}$ the main effect discernable is reduced blister size as compared with the equivalent neutral-only exposure. The temperature during exposure is a much stronger determinant of the blistering outcome than either pre- or post-annealing of the sample. The trends observed for neutralonly exposures are attributed to competing effects of defect density thermal equilibration and $\mathrm{H}$-atom induced modification of the Si layers. Energetic ions modify the blistering via (temperature dependent) enhancement of H-mobility and re-crystallization of amorphous Si.
\end{abstract}

\footnotetext{
${ }^{1}$ Corresponding author: M.A.Gleeson@differ.nl
} 


\section{Introduction}

Hydrogen-induced blistering of materials is a complex phenomenon ${ }^{1-3}$ that can have a strong dependence on the exposure conditions, with sample temperature being one of the critical parameters. The temperature dependence of blister formation is an open issue in fusion research where hydrogen retention ${ }^{4-6}$ and hydrogen-induced damage to plasma-facing materials $^{7-9}$ are being investigated. In relation to thin films, blister and crater formation occurs during annealing of hydrogenated Si-Ge multilayer (ML) structures ${ }^{10}$. Heating can induce structural modifications such as relaxation and crystalline phase transformation, promote diffusion and nucleation, and in the case of mixed-material systems induce intermixing and compound formation. All such changes influence the behaviour of hydrogen within the system.

The selection of appropriate annealing/exposure temperature is important for the process optimization in thin layer transfer techniques both for standard ion implantation and strained-layer driven layer detachment ${ }^{11-21}$. Localization of either hydrogen or stabilized vacancy complexes (depending on the specifics of the strain states) at interfaces in layered materials is a commonly observed phenomenon. It is proposed as a means of producing better quality thin silicon layers for silicon-on-insulator related applications ${ }^{18-20}$. Layer quality is improved because the use of buried interfaces to control detachment allows for significant reduction, or even elimination, of the energetic ion fluence required to induce delamination.

In this work we report on the influence of sample temperature on the development of blisters in $\mathrm{Mo} / \mathrm{Si} \mathrm{ML}$ samples. These samples are composed of alternating layers of nanometer thick amorphous $\mathrm{Si}\left(a-S_{i}\right)$ and polycrystalline Mo with mixed Mo-Si interfacial regions $^{22}$. They are susceptible to two distinct hydrogen-induced blistering processes ${ }^{23-26}$, which are attributed to the formation of $\mathrm{H}_{2}$-filled blisters and to the formation and clustering 
A.S. Kuznetsov, M. A. Gleeson and F. Bijkerk (2014). "Temperature dependencies of hydrogen-induced blistering of thin film multilayers." Journal of Applied Physics 115(17): 173510.

DOI: $10.1063 / 1.4875484$

of hydrogen-vacancy complexes producing void blister ${ }^{24}$. The former occurs under the influence of thermal H-atom irradiation; the latter process is observed when energetic (100's of $\mathrm{eV}$ ) ions are present in the irradiating flux. These processes are not entirely independent. In particular, the inclusion of energetic ions in the irradiating flux modifies the development and growth of $\mathrm{H}_{2}$-filled blisters ${ }^{24}$.

Hydrogen-induced blistering in such MLs is observed to be localized near the Moon-Si interfaces ${ }^{23}$. This is attributed the strained states and defects that are introduced near these interfaces by the transition between materials and the local atomic structures ${ }^{24}$. In the case of exposure to a neutral-only hydrogen flux, blistering was the result of layer delamination occurring exclusively at the outermost Mo-on-Si interface. When ions were also present in the irradiating flux delamination was observed at the outermost two Mo-onSi interfaces. Apart from direct penetration to the second and deeper bilayers, energetic ions were proposed to induce transport of hydrogen from gas-filled bubbles near the outermost Mo-on-Si interface across the mixed-phase interfacial region into the underlying Si layer.

A preliminary study on the temperature dependence of blister formation in $\mathrm{Mo} / \mathrm{Si}$ MLs illustrated that the substrate temperature had a significant impact on the formation of blisters $^{26}$. However, the complexity of the system left many open questions since the MLs themselves are subject to structural deterioration as a result of annealing ${ }^{27-29}$. This is primarily the result of increased intermixing at the interfaces resulting in the growth of molybdenum silicide layers at the expense of the individual Mo and Si layers. This induces an overall compaction of the ML structure as the silicide layers produced are more dense than those of their original elemental constituents.

This manuscript aims to provide a detailed evaluation of the influence of sample temperature on the formation of blisters in these structures. Atomic force microscopy 
A.S. Kuznetsov, M. A. Gleeson and F. Bijkerk (2014). "Temperature dependencies of hydrogen-induced blistering of thin film multilayers." Journal of Applied Physics 115(17): 173510.

DOI: $10.1063 / 1.4875484$

(AFM) measurements are used as the basis for evaluating the extent and type of blistering. Comparison is made between the temperature dependencies in the case of exposure to an exclusively neutral flux and to a flux containing energetic ions. In addition, the relative importance of the sample temperature during hydrogen irradiation as compared with either pre- or post-annealing of the sample at higher temperatures than during the actual exposure is studied. Substrate temperature during the exposure is demonstrated to have the biggest impact on the outcome.

\section{Experimental.}

The Mo/Si ML samples investigated in this work are similar to those studied previously $^{23-26}$. They were deposited on a super-polished Si wafer by magnetron sputtering with additional ion polishing of the deposited Si layers. The thicknesses of individual layers in the samples were $\sim 3 \mathrm{~nm}$ for Mo and $\sim 4 \mathrm{~nm}$ for Si. The samples were transferred through air both prior to and post hydrogen exposure and no pre-treatment step was applied before either exposure or analysis.

The hydrogen source was a capillary-type thermal cracker (Oxford Applied Research TC50). It was operated at a power of $55 \mathrm{~W}$ with a $1 \mathrm{SCCM} \mathrm{H}_{2}$ flow. In addition to the neutral atomic and molecular hydrogen flux, the source also produced an ion current on the order of $\sim 75 \mathrm{nA}$. The majority of ions produced have energies $>800 \mathrm{eV}$, due to the positive bias $(+1000 \mathrm{~V})$ used to e-beam heat the capillary ${ }^{24}$.

Samples were exposed for 5 hours to the unmodified hydrogen flux from the thermal capillary cracker at various set-point temperatures ranging from $50{ }^{\circ} \mathrm{C}$ to $275{ }^{\circ} \mathrm{C}$, under otherwise identical conditions. They were stabilized at the desired target temperature prior to commencing exposure. Heating was radiative, via a back-mounted filament and the 
temperature was monitored and controlled on the basis of a K-type thermocouple that was spot-welded to one of the sample mounting clamps. Similar exposures were performed with the addition of a biased deflector plate near to the sample and parallel to the incident particle direction. A bias of $-1100 \mathrm{~V}$ was used to deflect charged species from the flux prior to interaction with the surface. When the bias was applied the drain current measured on the sample during exposure dropped to $<1 \mathrm{nA}$. Exposures are characterized as "neutral-only" or "ion+ neutral" depending on whether the biased plate was present or absent, respectively.

Damage to exposed samples was typically evident to the naked eye as a discoloration/dulling of the original mirror-like surface. Regions covered by clamps during the exposure always appeared undamaged. Exposed samples were characterized by optical microscopy and atomic force microscopy (AFM). For samples exhibiting non-uniform damage, the analysis was performed in the region exhibiting the most damaged. In the current work this corresponds to the on-axis position of the cracker capillary. In cases where no damage was visible or where the damage appeared uniform, the analysis position was selected with reference to the non-uniform samples.

\section{Results.}

\subsection{Temperature dependencies of "ion+neutral" and "neutral-only" exposures.}

As reported in ${ }^{24}$, samples exposed to the ion+neutral flux at temperatures $\left(\mathrm{T}_{\text {exposure }}\right)$

of $85-100{ }^{\circ} \mathrm{C}$ typically exhibited a distinctive concentric damage pattern on the surface. This is primarily due to the presence of ions; when a neutral-only flux is used the damage across the exposed surface appears uniform. After the current ion+neutral exposures, the samples exposed at temperatures between $50{ }^{\circ} \mathrm{C}$ and $100{ }^{\circ} \mathrm{C}$ again exhibited the well-defined central spot surrounded by regions of more diffuse discoloration. Those exposed at $150{ }^{\circ} \mathrm{C}$ and 200 
${ }^{\circ} \mathrm{C}$ had a more uniform discoloration, but a central spot remained distinguishable under close inspection. The sample exposed at $250{ }^{\circ} \mathrm{C}$ appeared to have uniform damage, while no damage was apparent on the sample exposed at $275^{\circ} \mathrm{C}$. Thus, visual inspection qualitatively indicates that the influence of ions diminishes with increasing $\mathrm{T}_{\text {exposure. }}$.

In the case of the equivalent neutral-only exposures, no damage was evident after exposure at $50{ }^{\circ} \mathrm{C}$ and $75^{\circ} \mathrm{C}$. At $\mathrm{T}_{\text {exposure }}$ between $100{ }^{\circ} \mathrm{C}$ and $250{ }^{\circ} \mathrm{C}$ all samples exhibited uniform damage across the exposed surface, while the sample exposed at $275{ }^{\circ} \mathrm{C}$ again appeared undamaged. Figure 1 shows a comparison of optical microscopy images (magnification $\times 100)$ taken from these two sets of samples after exposure at temperatures ranging from 50 to $250{ }^{\circ} \mathrm{C}$. The left-hand-side (LHS) image segments are from samples exposed to the ion+ neutral flux, while the right-hand-side (RHS) segments are from samples exposed to the neutral-only flux.

An immediately obvious difference between the two sets of exposures is the absence of blistering after exposure to the neutral-only flux at $50{ }^{\circ} \mathrm{C}$ and $75{ }^{\circ} \mathrm{C}$ [Fig. 1(a)-(b), RHS]. The lowest $\mathrm{T}_{\text {exposure }}$ that was confirmed to produce visible damage after 5 hours of neutralonly exposure was $90^{\circ} \mathrm{C}$. It is further evident from the images that exposure to the ion + neutral flux at temperatures between $50{ }^{\circ} \mathrm{C}$ and $150{ }^{\circ} \mathrm{C}$ results in the formation of two distinct blister size distributions and that the larger of these is primarily comprised of double- or multi-component structures. It has already been demonstrated that both of these features are a consequence of the presence of ions in the irradiating flux ${ }^{24}$. This is reconfirmed by Fig. 1(c)-(d), which illustrate that the deflection of ions results in the disappearance of the smaller of the two size distributions and the absence of multicomponent structures. The resultant "neutral-only" blistering is characterized by a single size distribution composed of symmetric single-component blisters. Following ${ }^{24}$, the smaller of 
the two distributions is designated as "ion-induced" (void) and the larger as "thermal neutral” ( $\mathrm{H}_{2}$-filled), signifying the most crucial incident species necessary for the development of the respective blisters. The designations are not exclusive since Fig. 1(a)-(b) demonstrates that the development of "thermal neutral" blisters is stimulated at lower $\mathrm{T}_{\text {exposure }}$ when ions are present.

Figure 2 shows plots of blister dimensions (volume versus area) derived from AFM scans of the samples shown in Fig. 1. In the case of the ion+neutral exposures, blisters designated as "ion-induced" and "thermal neutral" are distinguished using different markers. It is possible to make this distinction on the basis of blister size and aspect ratio for $\mathrm{T}_{\text {exposure }}$ up to $150{ }^{\circ} \mathrm{C}$. At higher temperatures only a single blister size distribution is apparent, which is designated as "thermal neutral". Compared to the equivalent neutral-only exposures there is more scatter in the volume-to-area data of "thermal neutral" blisters formed during ion+neutral irradiation. This is a consequence of the formation of multi-component structures. The solid line on these and subsequent figures is a reference curve, which was derived in an earlier report ${ }^{24}$. It is included to aid comparison between the different exposures both within this work and with those previously reported.

Multi-component structures are attributed to the introduction of an ion-induced transport mechanism that transfers hydrogen trapped in gas filled bubbles at the outer most Mo-on-Si interface to deeper layers ${ }^{24}$. It is evident from inspection of Fig. 1 that the size of the smaller component(s) of such blisters decreases relative to that of the larger component with increasing temperature. At $\mathrm{T}_{\text {exposure }} \geq 200^{\circ} \mathrm{C}$ only single-component blisters appears to be present even in the case of the ion+neutral exposures. The evolution of 'double-blister' structures was evaluated for $\mathrm{T}_{\text {exposure }}$ between 50 and $150{ }^{\circ} \mathrm{C}$ on the basis of the radii of the two individual component measured from 10 distinct features on AFM scans. Figure 3 
A.S. Kuznetsov, M. A. Gleeson and F. Bijkerk (2014). "Temperature dependencies of hydrogen-induced blistering of thin film multilayers." Journal of Applied Physics 115(17): 173510.

DOI: $10.1063 / 1.4875484$

shows the resultant averaged absolute radii of the two components, while the inset shows the corresponding ratio. While both blister components grow in absolute terms with increasing exposure temperature, the larger component grows faster than the smaller one. Consequently, the ratio drops from $\sim 0.8$ to $\sim 0.45$ over this temperature range. This again points to ion-induced effects becoming comparatively less effective with increasing $T_{\text {exposure }}$.

Figure 4 provides an overview of the evolution of blister characteristics as a function of exposure temperature: (a) the blister count, (b) the total blister volume, and (c) the average volume per blister. For both flux compositions, the area number density of blisters decreases with increasing $T_{\text {exposure }}$ across the full range. The size of the individual blisters

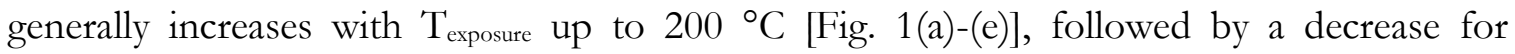
$\mathrm{T}_{\text {exposure }}=250{ }^{\circ} \mathrm{C}$ [Fig. 1(f)]. This is reflected in changes in the total and average volumes as a function of exposure temperature. Elastic recoil detection (ERD) analysis of the samples exposed to the ion +neutral flux indicate that the sample exposed at $150{ }^{\circ} \mathrm{C}$ retained the highest $\mathrm{H}$-content in the outermost layers, whereas the largest individual blisters are observed after $\mathrm{T}_{\text {exposure }}=200{ }^{\circ} \mathrm{C}$. This is consistent with previous results, which also illustrate the absence of a simple correlation between total H-content and the development and growth of blisters ${ }^{25}$.

With regard to the influence of flux composition, the general characteristic that can be identified is that the presence of ions promotes the development of $\mathrm{H}_{2}$-filled blisters at $\mathrm{T}_{\text {exposure }} \leq 100^{\circ} \mathrm{C}$, while retarding them at $\geq 150^{\circ} \mathrm{C}$. No blisters are directly attributed to ions at $\mathrm{T}_{\text {exposure }} \geq 200{ }^{\circ} \mathrm{C}$, although their presence is still evident from the number and size of the "thermal neutral" blisters. The discontinuity in the blister count at $\mathrm{T}_{\text {exposure }}=200{ }^{\circ} \mathrm{C}$ indicates 
that extra blisters are still being formed as a consequence of the ion irradiation. These are not distinguishable from "thermal neutral" blisters on the basis of either size or shape.

\subsection{Effects of pre- and post-exposure annealing}

The effects on blistering of pre- and post-annealing of samples to elevated temperature was investigated. Pre-annealing highlights the influence of thermally-induced changes to the layered structure (e.g. layer compaction and intermixing), while postannealing probes temperature-driven redistribution of incorporated hydrogen. For the preannealing studies, samples were held at temperatures $\left(\mathrm{T}_{\text {anneal }}\right)$ of $200{ }^{\circ} \mathrm{C}, 250{ }^{\circ} \mathrm{C}, 300{ }^{\circ} \mathrm{C}$, and $400{ }^{\circ} \mathrm{C}$ for 5 hours prior to exposure to the ion + neutral flux for 5 hours at $100{ }^{\circ} \mathrm{C}$. The post-annealing experiment was conducted by first exposing a sample to the ion + neutral flux for 5 hours at $100{ }^{\circ} \mathrm{C}$ followed by annealing at $250{ }^{\circ} \mathrm{C}$ for 5 hours.

Figure 5 shows a comparison of AFM images taken from a sample exposed without pre-/post-annealing (a), and from samples that were pre-annealed at (b) $200{ }^{\circ} \mathrm{C}$ and (c) 300 ${ }^{\circ} \mathrm{C}$, and post-annealed at (d) $250{ }^{\circ} \mathrm{C}$. The sample pre-annealed to $400{ }^{\circ} \mathrm{C}$ showed no visible damage after exposure. The absence of blistering in that case is attributed to destruction of the ML structure due to intermixing (see Discussion).

Figure 6 shows the comparison of individual blister volume versus area derived from these samples. Pre-annealing produces a discernable change in the aspect ratio of the "thermal neutral" blisters, as indicated by the shift of the data points above the reference curve. In case of post-annealing the data points for "thermal neutral" blisters remain below the reference curve, but exhibit significant growth. In general, both pre- and post-annealing results in a reduced scatter in the "thermal neutral" data points. This is due to changes to the relative sizes of multi-component blisters that are discernable on Fig. 5. In both cases the 
A.S. Kuznetsov, M. A. Gleeson and F. Bijkerk (2014). "Temperature dependencies of hydrogen-induced blistering of thin film multilayers." Journal of Applied Physics 115(17): 173510.

DOI: $10.1063 / 1.4875484$

size of the smaller component(s) is reduced relative to the larger component. For preannealing this is mainly due to a reduction in the size of the smaller components, pointing to inhibition of the ion-induced transport mechanism. In the case of post-annealing, the change is the result of preferential growth of the larger component (compare Fig. 5 (a)\&(d)).

Figure 7 provides an overview of blister characteristics. The number of blisters formed decreases with increasing pre-annealing temperature. The effect is most pronounced for the "thermal neutral" blisters; the number of "ion-induced" blisters formed is relatively unaffected by pre-annealing. The total volume occupied by "thermal neutral" blisters is unchanged by pre-annealing at $200{ }^{\circ} \mathrm{C}$, but the average blister volume increases significantly. Both are decreased by pre-annealing to higher temperatures. The total volume occupied by "ion-induced" blisters is almost doubled as a consequence of the $200{ }^{\circ} \mathrm{C}$ pre-anneal. It decreases again at higher pre-anneal temperatures, returning to the level of the un-annealed sample in the case of pre-annealing at $300^{\circ} \mathrm{C}$.

Post-annealing results in an increase in the number of both "ion-induced" $(\sim 14 \%)$, and "thermal neutral" $(\sim 17 \%)$ blisters. The characteristic volumes (total and average) occupied by "ion-induced" blisters are not dramatically altered, whereas there is a substantial increase in those of the "thermal neutral" blisters.

\section{Discussion}

\section{Blistering processes.}

We begin by giving a synopsis of our previous observations and interpretations of blister formation in Mo/Si MLs, before addressing how those processes are influenced by temperature-dependent effects. The main steps in "thermal neutral" blistering can be summarized as: 
A.S. Kuznetsov, M. A. Gleeson and F. Bijkerk (2014). "Temperature dependencies of hydrogen-induced blistering of thin film multilayers." Journal of Applied Physics 115(17): 173510.

DOI: $10.1063 / 1.4875484$

- Trapping of $\mathrm{H}$ atoms at the surface of the outermost Si layer.

- Diffusion of $\mathrm{H}$ atoms through the Si layer; some $\mathrm{H}$ atoms will be trapped in the layer by strained and dangling bonds.

- Diffusion of $\mathrm{H}$ atoms through the Mo layer, with trapping at defect sites and grain boundaries; segregation of $\mathrm{H}$ atoms to vacancies and formation of $\mathrm{H}_{2}$ molecules.

- Preferential accumulation of $\mathrm{H}_{2}$ at stressed centres in the vicinity of outermost Moon-Si interface; growth of $\mathrm{H}_{2}$-filled bubbles by strain-driven accumulation from the overlying Mo layer.

Figure 8 (a) shows simplified picture of the blistering process during neutral-only exposures. Figure 8(b) illustrates how the blistering process is modified when the incident flux also contains energetic ions. Ion influences can be summarized as follows:

- Enhanced hydrogen uptake by the creation of defects and active sites at the surface; introduction of vacancies and defects by the ion collision cascade in both the $\mathrm{Si}$ and Mo layers modify H-mobility.

- Creation of trap sites in Mo and Si that can retard blister formation by sequestration of hydrogen across multiple (new) "sinks". Si dangling bonds can trap H; Mo vacancies can interact with diffusing $\mathrm{H}$ atoms to form stable hydrogen-vacancy $(\mathrm{H}$ V) complexes.

- Macroscopic void blisters develop due to coalescence of mobile H-V complexes with preferentially nucleation at stressed centres near the Mo-on-Si interfaces.

- Ion-induced defects facilitate the formation of the 'multi-component' blisters by stimulating the transport of hydrogen from gas-filled blisters to deeper layers. 
A.S. Kuznetsov, M. A. Gleeson and F. Bijkerk (2014). "Temperature dependencies of hydrogen-induced blistering of thin film multilayers." Journal of Applied Physics 115(17): 173510.

DOI: $10.1063 / 1.4875484$

Energetic ions affect $a-S i$ primarily via the introduction and removal of the defect structures necessary for efficient transport of hydrogen through the network. Ion irradiation induces the release of implanted hydrogen from strongly-bound defect complexes ${ }^{30}$. The resultant diffusion and attachment to vacancy defects enhances the effective mobility of $\mathrm{H}$ in Si. In a related manner, the presence of ions results in ion-assisted uptake of hydrogen. Such processes have been discussed, for instance, in the context of uptake measurements in case of $\mathrm{D}$ bombardment of carbon materials ${ }^{31}$. It was proposed that ions promote trapping via the creation of 'active sites' at the surface by inelastic interaction with the sample. Neutral deuterium, trapped by this mechanism filled both pre-existing traps in the sample and ioninduced traps formed due to the energetic ion bombardment.

\section{Temperature dependencies}

For the current samples, the temperature during exposure is a much stronger determinant of the outcome of hydrogen-induced blistering than either pre- or postannealing. Temperature-dependence in blistering of materials can arise due to changes in the relative contributions from competing effects. The temperature dependencies we report can be accounted for on the basis of defect densities established as a function of $\mathrm{T}_{\text {exposure }}$ and/or $\mathrm{T}_{\text {anneal }}$ and exposure-induced modifications to the layer structure.

a-Si layers are known to exhibit a temperature-dependent defect density, which establishes an equilibrium above a threshold temperature $\left(T_{E}\right)$. In the case of thick a-Si layers, $\mathrm{T}_{E}$ is typically in vicinity of $\sim 200{ }^{\circ} \mathrm{C}^{32-35}$. The defect density increases with temperature above this threshold, while at lower temperature it is generally determined by the thermal history of the sample. 
Heya et al. have demonstrated that H-atom irradiation of a-Si films during annealing can induce crystallization at temperatures $<350{ }^{\circ} \mathrm{C}^{36,}{ }^{37}$. The induced transition to a hydrogenated microcrystalline phase $(\mu c-S i: \mathrm{H})$ was also observed during real time monitoring by infrared spectroscopy while irradiating at $200{ }^{\circ} \mathrm{C}^{38}$. Formation of $\mu c-S i: \mathrm{H}$ during magnetron deposition in an hydrogen-rich atmosphere is typically performed at substrate temperatures in the $150-350{ }^{\circ} \mathrm{C}$ range. Exposure of hydrogenated amorphous silicon $(a-S i: \mathrm{H})$ films to hydrogen plasma at elevated temperatures $(>500 \mathrm{~K})$ can also result in crystallization $^{39,40}$. The process is driven by structural relaxation arising from $\mathrm{H}$ insertion to strained Si-Si bonds and in bond-centered position between unbonded Si atoms ${ }^{41}$.

In a study on the temperature dependence of plasma hydrogenation-driven layer separation using a buried SiGe strain layer, Di et al identified a temperature window in which the separation was effective $e^{42}$. On the low temperature side $\left(\leq 250{ }^{\circ} \mathrm{C}\right)$, trapping of hydrogen at vacancy defects in the "capping" Si layer hindered diffusion to the strained layer. On the high temperature side $\left(\geq 400{ }^{\circ} \mathrm{C}\right)$ localization was limited by hydrogen dissociation from defects and $\mathrm{H}_{2}$ loss via out-diffusion. The onset of thermal desorption from a-Si materials is typically $\geq 350{ }^{\circ} \mathrm{C}^{43}$.

As noted above, defects introduced by energetic ions modify the uptake and mobility of hydrogen by the ML. Consequently, dynamic annealing (i.e. the evolution in time of defects following their introduced by an ion collision cascade) influences the blistering outcome of hydrogen ion irradiated samples. Defects typically have a characteristic lifetime. For instance, Myer et al. determined a characteristic time constant of $6 \mathrm{~ms}$ for dynamic annealing of crystalline $\mathrm{Si}$ at room temperature ${ }^{44}$. The lifetime decreases with increasing temperature. 
Giguère and Terreault illustrated that dynamic annealing during irradiation could significantly enhance ion-induced blistering of $\mathrm{Si}^{45}$. The effects were attributed to the introduction of strain structures and the enhancement of $\mathrm{H}$ mobility via radiation enhanced diffusion. Creation of strained structures contributes to the enhancement of hydrogen diffusion through a-Si. Ab initio simulations of $\mathrm{H}$ in $a-S i$ and $a-S i: \mathrm{H}$ show a strong tendency to attacked strained bond structures in the network ${ }^{46}$. Formation of $\mathrm{H}_{2}$ in large voids with excess H-content was also observed. Based on studies hydrogen diffusion in nano-structured a-Si, Kail et $a t^{47}$ proposed that molecular diffusion might be the dominant process in microcrystalline Si.

The results presented in this report can be interpreted in light of these known (temperature-dependent) effects of hydrogen ions and neutrals on a-Si layers. We note that the current layers are nano-scaled. Hence the critical temperatures identified above for thick a-Si layers and (defected) crystalline Si must be considered as indicative rather than absolute.

\section{Effects of $T_{\text {exposure }}$}

Neutral-only exposures are somewhat analogous to plasma hydrogenation, except that even low energy ion effects are absent. Only "thermal neutral" blisters were observed to develop on samples exposed to this flux. For the current exposure conditions these blisters have an appearance threshold at $\mathrm{T}_{\text {exposure }} \sim 90^{\circ} \mathrm{C}$. At higher temperatures two regimes can be distinguished: a growth phase for $\mathrm{T}_{\text {exposure }}$ up to $200{ }^{\circ} \mathrm{C}$ and a decline phase for $\mathrm{T}_{\text {exposure }}>200$ ${ }^{\circ} \mathrm{C}$. In addition to thermal relaxation of layers and intermixing at the interfaces, the processes that are operative during neutral-only exposure will be defect density thermal equilibration and $\mathrm{H}$-atom induced hydrogenation of $a-S i$ and crystallization to $\mu c-S i: \mathrm{H}$. The combination of these effects is sufficient to account for the observed temperature dependencies. 
In the "growth phase" $\left(100-200^{\circ} \mathrm{C}\right)$ thermal equilibration results in an increasing defect density in the $a-S i$ layers with increasing sample temperature. This promotes the transport of atomic hydrogen through the outermost Si to the underlying Mo layer where accumulation in vacancies and defects produces $\mathrm{H}_{2}$ filled bubbles. Preferential accumulation at strained centers associated with the Mo-on-Si interface leads to the development of macroscopic blisters. The a-Si overlayer hinders out-diffusion of $\mathrm{H}_{2}$ from the Mo layer.

Increasing temperature enhances the effective lateral diffusion of hydrogen, leading to formation of bigger blisters with lower number density. The increasing individual size and decreasing number density of blisters with increasing $\mathrm{T}_{\text {exposure }}$ implies preferential accumulation at certain nucleation sites at the expense of others. In the current case, the objects being observed are macroscopic surface modifications. As demonstrated by figure 5(d), these features do not dissipated with post-exposure annealing and the growth of large blisters does not go at the expense of smaller ones. However, the size and number density of blisters formed as a function of $\mathrm{T}_{\text {exposure }}$ will still reflect processes, such as Ostwald ripening and preferential consumption of hydrogen from the surroundings, that are operative during the pre-blister clustering stage $e^{48,49}$.

The "decline phase" $\left(>200{ }^{\circ} \mathrm{C}\right)$ can be attributed to H-induced crystallization of the a-Si layer, retarding the uptake and transport of $\mathrm{H}$-atoms. In the first instance this will counteract thermal defect equilibration by reducing the average defect density in the layer. Furthermore, if the main diffusion mechanism in $\mu c-S i: \mathrm{H}$ is indeed via $\mathrm{H}_{2}{ }^{47}$, crystallization will provide an escape route for the molecules formed in this and the underlying Mo layer, retarding the development of $\mathrm{H}_{2}$ filled blisters.

The inclusion of energetic ions in the irradiating flux modifies the development of "thermal neutral" blisters by reducing their onset temperature while simultaneously retarding 
their growth at higher temperatures $\left(\geq 150^{\circ} \mathrm{C}\right)$. The reduced onset temperature can be attributed to ion-enhanced $\mathrm{H}$ uptake and transport due to the introduction of new defect sites and strained bonds into the $a$-Si. The effects diminish with increasing temperature due to more rapid dynamic annealing. The presence of ions also reduces the onset temperature for a-Si:H crystallization and accelerates crystallization and structural relaxation at a given temperature. These structural changes again retard the development of thermal-neutral blisters relative to the equivalent neutral-only exposure by reducing diffusion of $\mathrm{H}$ to deeper layers and enhancing re-emission of $\mathrm{H}_{2}$ from the $\mathrm{ML}$ structure.

Ion-induced production of $\mathrm{H}-\mathrm{V}$ complexes in both the $\mathrm{Si}$ and Mo layers is an additional factor in the slower growth of "thermal neutral" blisters with increasing $\mathrm{T}_{\text {exposure }}$ by consuming hydrogen that might otherwise contribute to the growth of gas-filled bubbles. H$\mathrm{V}$ complexes are necessary for the formation of void blisters. Dynamic annealing modifies the evolution and nucleation behaviour of such complexes ${ }^{42,50}$. While blisters clearly identifiable as "ion-induced" are not evident at $\mathrm{T}_{\text {exposure }}>150^{\circ} \mathrm{C}$ ion-induced pre-blister voids may still act to sequester hydrogen, thereby retarding $\mathrm{H}_{2}$-filled blister growth.

\section{Effects of pre-/post-annealing}

Pre-annealing induces structural changes to the ML stack via silicide formation at the interfaces, with the effect becoming more pronounced with increasing temperature. An annealing study on e-beam deposited Mo/Si MLs exhibited an initial period of rapid (0-10 hours) compaction that was attributed to compound rearrangement at the interfaces, followed by a slower diffusion-limited process of interface growth ${ }^{27}$. Gradual expansion of the interfaces occurs in $\mathrm{Mo} / \mathrm{Si} \mathrm{ML}$ during annealing to temperatures up to $\sim 300{ }^{\circ} \mathrm{C}$. Above 
A.S. Kuznetsov, M. A. Gleeson and F. Bijkerk (2014). "Temperature dependencies of hydrogen-induced blistering of thin film multilayers." Journal of Applied Physics 115(17): 173510.

DOI: $10.1063 / 1.4875484$

$300{ }^{\circ} \mathrm{C}$ an abrupt change occurs, which is attributed to a transformation to hexagonal $\mathrm{MoSi}_{2}$ (b-MoSi 2 ) associated with reaching a critical Mo-on-Si interface thickness of $2 \mathrm{~nm}^{28,29}$.

Pre-annealing of samples introduces defects to the a-Si layers via defect equilibration. In principle, the defect density established by pre-annealing becomes a constant after any $\mathrm{T}_{\text {anneal }}$ that exceeds the equilibration threshold. Vergnar et al. have investigated hydrogen diffusion and material densification in $a-S i$ as a function of temperature $e^{51}$. Both processes became appreciable in the $200-250{ }^{\circ} \mathrm{C}$ temperature range. As silicon diffusivities were an order of magnitude lower than those of hydrogen, hydrogen diffusion always preceded densification. Pre-annealing ensures that some layer densification, which reduces H-mobility, can occur prior to the addition of hydrogen to the system. Thus, defect equilibration contributes to enhanced hydrogen mobility in a-Si but the effect is counteracted with increasing $\mathrm{T}_{\text {anneal }}$ by interfacial layer growth and densification.

Pre-annealing results in a significant decrease in the number of "thermal neutral" blisters formed, while having a relatively minor effect of the number of "ion-induced" blisters. The reduced number density of "thermal neutral" blisters indicates removal of strained states and potential nucleation sites during the pre-annealing stage. It is noteworthy that pre-annealing results in a clear change in the aspect ratio of "thermal neutral" blisters (figure 6(b)\&(c)). They shift above the reference curve on the volume-to-area data plot and begin to follow a trend that is similar to that of the "ion-induced" blisters. This can be attributed to structural relaxation of the layers.

Fig. 5 shows that double-blister structures become much less pronounced with increasing pre-exposure $\mathrm{T}_{\text {anneal }}$ and are almost absent in the sample after $\mathrm{T}_{\text {anneal }}=300{ }^{\circ} \mathrm{C}$. This points to a significantly increased barrier to ion-induced transport across the Mo-on-Si interface due to the increased interfacial-layer thicknesses. No blister formation was 
observed on a sample that was pre-annealed to $400{ }^{\circ} \mathrm{C}$. This temperature is sufficient to completely transform the Si layers to crystalline $b-\mathrm{MoSi}_{2}$, relaxing the structure ${ }^{29}$. The absence of distinct interfaces and enhanced $\mathrm{H}_{2}$ mobility afforded by the crystallization prevents the depth-localized development of blisters.

In the case of post-annealing, the characteristic volumes of the "ion-induced" blisters are largely unaffected (although the number of such blisters increases). In contrast, the characteristic volumes of "thermal neutral" blisters increase substantially. This is consistent with the attribution of these blisters to redistribution of hydrogen trapped in voids and vacancies in the outermost Mo layer ${ }^{25}$, a process that is enhanced by the elevated postexposure temperature. Only the larger component of multi-component blisters exhibit growth. The smaller components do not change because the transport mechanisms that feed these features require the presence of energetic ions.

The changes observed as a result of pre-/post-annealing are relatively minor in comparison to the influence of the sample temperature during the actual exposure (contrast Figs. 1 and 5). Thus, the effect of temperature on the uptake and distribution of hydrogen during the exposure is far more critical in determining the size and number of blisters formed than thermally-induced structural and chemical modification to the ML. This is emphasized by the fact that blisters did not develop on the sample that was exposed at 275 ${ }^{\circ} \mathrm{C}$ whereas they did appear on the sample that was pre-annealed at $300{ }^{\circ} \mathrm{C}$ followed by exposure at $100^{\circ} \mathrm{C}$ (figure $\left.5(\mathrm{c})\right)$.

\section{Conclusion.}

Evaluation of the effects of sample temperature on hydrogen-induced blister formation in $\mathrm{Mo} / \mathrm{Si}$ multilayer (ML) samples illustrates that the temperature during exposure 
is the dominating factor in the development of blisters. Effects related to thermally-induced changes to the ML structure and post-exposure redistribution of incorporated hydrogen are of lesser importance.

The general trends observed for increasing exposure temperature were of an increase in blister size and a decrease in areal number density up to $200{ }^{\circ} \mathrm{C}$, followed by a decrease in blister size there-after. In the case of the neutral-only exposures, these trends are attributed to the competing effects on $a$-Si layers of defect density thermal equilibration (enhancing $\mathrm{H}$ uptake and mobility) and $\mathrm{H}$-atom induced re-crystallization (reducing $\mathrm{H}$ diffusion and enhancing $\mathrm{H}_{2}$ out-diffusion). The inclusion of ions in the irradiating flux enhances blister formation at lower temperatures by introducing defects and strained bond that promote $\mathrm{H}$ uptake and diffusion. At higher temperatures the presence of ions retards the growth of $\mathrm{H}_{2-}$ filled blisters relative to the neutral-only exposures. Two effects contribute to this: more rapid dynamic annealing reduces the impact of ion-induced defects and $\mathrm{H}-\mathrm{V}$ complexes at higher temperatures, and ion enhancement of $a-S i$ crystallization facilitates more effective out-diffusion of $\mathrm{H}_{2}$ from the layered structure.

\section{References}

1. J. B. Condon and T. Schober, J. Nucl. Mat. 207, 1 (1993).

2. B. Terreault, Phys. Status Solidi A 204 (7), 2129 (2007).

3. $\quad$ S. Dhara, Crit. Rev. Solid State 32 (1-2), 1 (2007).

4. R. A. Causey, D. F. Cowgill, R. Doerner, R. Kolasinski, B. Mills, D. Morse, J. Smugeresky, W. R. Wampler, R. Williams and D. Huber, J. Nucl. Mater. 415 (1), S672 (2011).

5. E. Igarashi, Y. Nishikawa, T. Nakahata, A. Yoshikawa, M. Oyaidzu, Y. Oya and K. Okuno, J. Nucl. Mater. 363-365, 910 (2007).

6. Y. Oya, H. Miyauchi, T. Suda, Y. Nishikawa, A. Yoshikawa, S. Tanaka and K. Okuno, Fusion Eng Des 82 (15-24), 2582 (2007).

7. V. K. Alimov, W. M. Shu, J. Roth, S. Lindig, M. Balden, K. Isobe and T. Yamanishi, J. Nucl. Mater. 417 (1-3), 572 (2011). 
8. V. K. Alimov, B. Tyburska-Puschel, S. Lindig, Y. Hatano, M. Balden, J. Roth, K. Isobe, M. Matsuyama and T. Yamanishi, J. Nucl. Mater. 420 (1-3), 519 (2012).

9. W. M. Shu, K. Isobe and T. Yamanishi, Fusion Eng. Des. 83 (7-9), 1044 (2008).

10. C. Frigeri, M. Serenyi, N. Q. Khanh, A. Csik, F. Riesz, Z. Erdelyi, L. Nasi, D. L. Beke and H. G. Boyen, Nanoscale Res. Lett. 6 (1), 189 (2011).

11. I. P. Ferain, K. Y. Byun, C. A. Colinge, S. Brightup and M. S. Goorsky, J. Appl. Phys. 107 (5), 054315 (2010).

12. P. Chen, Z. F. Di, M. Nastasi, E. Bruno, M. G. Grimaldi, N. D. Theodore and S. S. Lau, Appl. Phys. Lett. 92 (20), 202107 (2008).

13. H. J. Woo, H. W. Choi, W. Hong, J. H. Park and C. H. Eum, Surf. Coat. Technol. 203 (17-18), 2375 (2009).

14. S. Hayashi, D. Bruno and M. S. Goorsky, Appl. Phys. Lett. 85 (2), 236 (2004).

15. J. H. Liang, C. H. Hu, C. Y. Bai, D. S. Chao and C. M. Lin, Physica B 407 (15), 3020 (2012).

16. K. Shcherbachev and M. J. Bailey, Phys. Status Solidi A-Appl. Mat. 208 (11), 2576 (2011).

17. R. Singh, S. H. Christiansen, O. Moutanabbir and U. Gosele, J. Electron. Mater. 39 (10), 2177 (2010).

18. F. Okba, N. Cherkashin, Z. Di, M. Nastasi, F. Rossi, A. Merabet and A. Claverie, Appl. Phys. Lett. 97 (3), 031917 (2010).

19. L. Shao, Y. Lin, J. K. Lee, Q. X. Jia, Y. Q. Wang, M. Nastasi, P. E. Thompson, N. D. Theodore, P. K. Chu, T. L. Alford, J. W. Mayer, P. Chen and S. S. Lau, Appl. Phys. Lett. 87 (9), 091902 (2005).

20. L. Shao, Y. Lin, J. G. Swadener, J. K. Lee, Q. X. Jia, Y. Q. Wang, M. Nastasi, P. E. Thompson, N. D. Theodore, T. L. Alford, J. W. Mayer, P. Chen and S. S. Lau, Appl. Phys. Lett. 87 (25), 251907 (2005).

21. M. K. Weldon, V. E. Marsico, Y. J. Chabal, A. Agarwal, D. J. Eaglesham, J. Sapjeta, W. L. Brown, D. C. Jacobson, Y. Caudano, S. B. Christman and E. E. Chaban, J. Vac. Sci. Technol. B 15 (4), 1065 (1997).

22. R. W. E. van de Kruijs, E. Zoethout, A. E. Yakshin, I. Nedelcu, E. Louis, H. Enkisch, G. Sipos, S. Mullender and F. Bijkerk, Thin Solid Films 515 (2), 430 (2006).

23. A. S. Kuznetsov, M. A. Gleeson and F. Bijkerk, J. Phys.: Condens. Matter 24 (5), 052203 (2012).

24. A. S. Kuznetsov, M. A. Gleeson and F. Bijkerk, J. Appl. Phys. 114 (11), 113507 (2013).

25. A. S. Kuznetsov, M. A. Gleeson and F. Bijkerk, Thin Solid Films 545, 571 (2013).

26. A. S. Kuznetsov, M. A. Gleeson, R. W. E. van de Kruijs and F. Bijkerk, Proc. SPIE 8077 (1), 807713 (2011).

27. S. Bruijn, R. W. E. van de Kruijs, A. E. Yakshin and F. Bijkerk, Appl. Surf. Sci. 257 (7), 2707 (2011).

28. I. Nedelcu, R. de Kruijs, A. E. Yakshin and F. Bijkerk, J. Appl. Phys. 103 (8), 083549 (2008).

29. I. Nedelcu, R. W. E. van de Kruijs, A. E. Yakshin and F. Bijkerk, Phys. Rev. B 76 (24), 245404 (2007). 
30. Z. F. Di, Y. Q. Wang, M. Nastasi, L. Shao, J. K. Lee and N. D. Theodore, Appl. Phys. Lett. 93 (10), 104103 (2008).

31. A. Airapetov, L. Begrambekov, C. Brosset, J. P. Gunn, C. Grisolia, A. Kuzmin, T. Loarer, M. Lipa, P. Monier-Garbet, P. Shigin, E. Tsitrone and A. Zakharov, J. Nucl.

Mater. 390-391, 589 (2009).

32. A. Hadjadj, G. Djellouli and O. Jbara, Appl. Phys. Lett. 97 (21), 211906 (2010).

33. S. Vignoli, R. Meaudre and M. Meaudre, Phys. Rev. B 50 (11), 7378 (1994).

34. M. Meaudre, P. Jensen and R. Meaudre, Philos. Mag. B 63 (4), 815 (1991).

35. R. A. Street and K. Winer, Phys. Rev. B 40 (9), 6236 (1989).

36. A. Heya, A. Masuda and H. Matsumura, J. Non-Cryst. Solids 266-269, 619 (2000).

37. A. Heya, A. Masuda and H. Matsumura, Appl. Phys. Lett. 74 (15), 2143 (1999).

38. M. Katiyar and J. R. Abelson, Mater. Sci. Eng. A 304-306, 349 (2001).

39. S. Sriraman, M. S. Valipa, E. S. Aydil and D. Maroudas, J. Appl. Phys. 100 (5), 053514 (2006).

40. S. Sriraman, S. Agarwal, E. S. Aydil and D. Maroudas, Nature 418 (6893), 62 (2002).

41. M. S. Valipa, S. Sriraman, E. S. Aydil and D. Maroudas, J. Appl. Phys. 100 (5), 053515 (2006).

42. Z. F. Di, Y. Q. Wang, M. Nastasi, F. Rossi, L. Shao and P. E. Thompson, Appl. Phys. Lett. 93 (25), 254104 (2008).

43. E. H. C. Ullersma, P. Ullersma and F. H. P. M. Habraken, Phys. Rev. B 61 (15), 10133 (2000).

44. M. T. Myers, S. Charnvanichborikarn, L. Shao and S. O. Kucheyev, Phys. Rev. Lett. 109 (9), 095502 (2012).

45. A. Giguère and B. Terreault, J. Appl. Phys. 102 (10), 106106 (2007).

46. S. Chakraborty and D. A. Drabold, Phys. Rev. B 79 (11), 115214 (2009).

47. F. Kail, J. Farjas, P. Roura and P. R. I. Cabarrocas, Phys. Rev. B 80 (7), 073202 (2009).

48. J. Grisolia, G. B. Assayag, A. Claverie, B. Aspar, C. Lagahe and L. Laanab, Appl. Phys. Lett. 76 (7), 852 (2000).

49. J. G. Swadener, M. I. Baskes and M. Nastasi, Phys. Rev. B 72 (20), 201202 (2005).

50. Z. F. Di, M. Q. Huang, Y. Q. Wang and M. Nastasi, Appl. Phys. Lett. 97 (19), 194101 (2010).

51. M. Vergnat, S. Houssaini, G. Marchal, P. Mangin and C. Vettier, Phys. Rev. B 47 (12), 7584 (1993). 


\section{(a) $50{ }^{\circ} \mathrm{C}$}

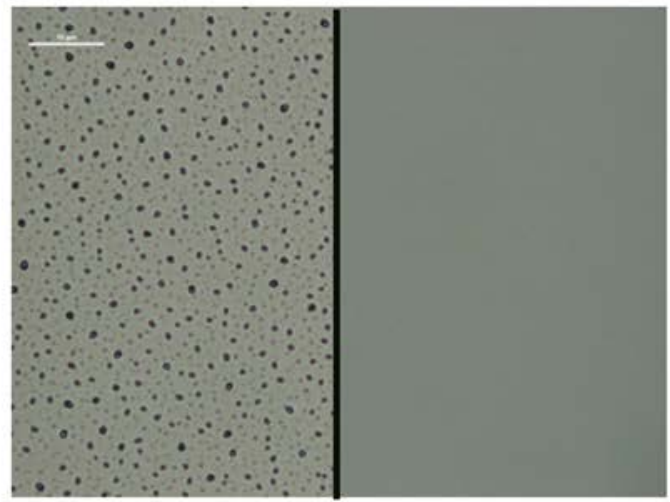

(c) $100{ }^{\circ} \mathrm{C}$

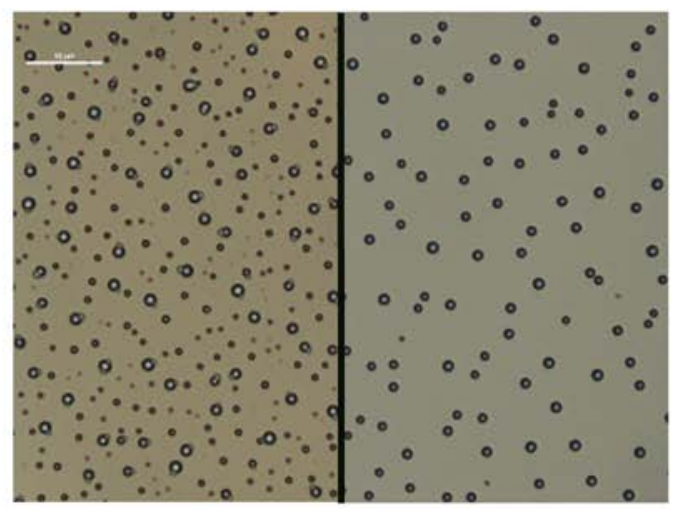

(e) $200^{\circ} \mathrm{C}$

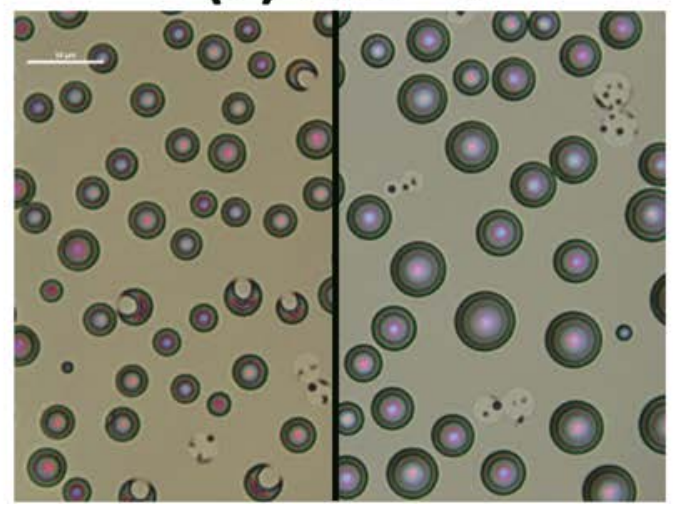

(b) $75{ }^{\circ} \mathrm{C}$

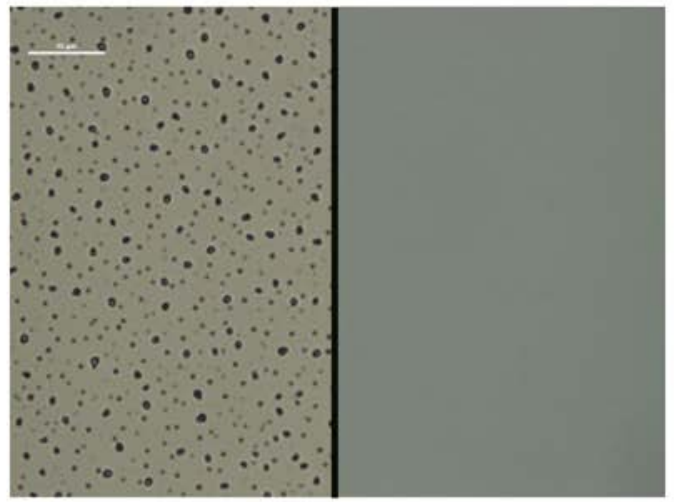

(d) $150^{\circ} \mathrm{C}$

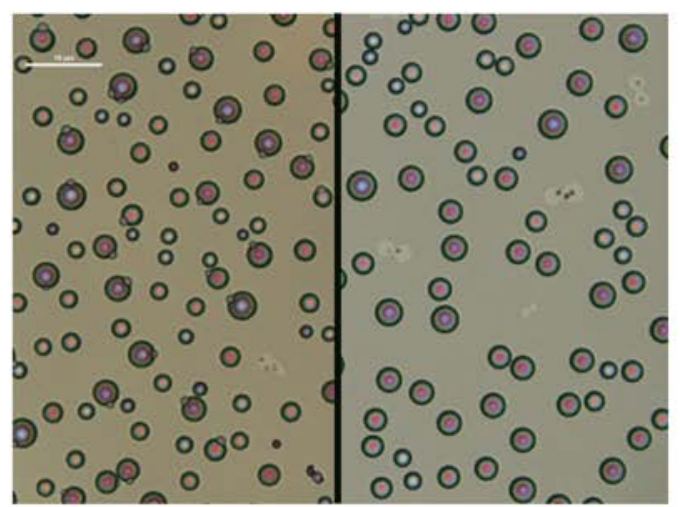

(f) $250^{\circ} \mathrm{C}$

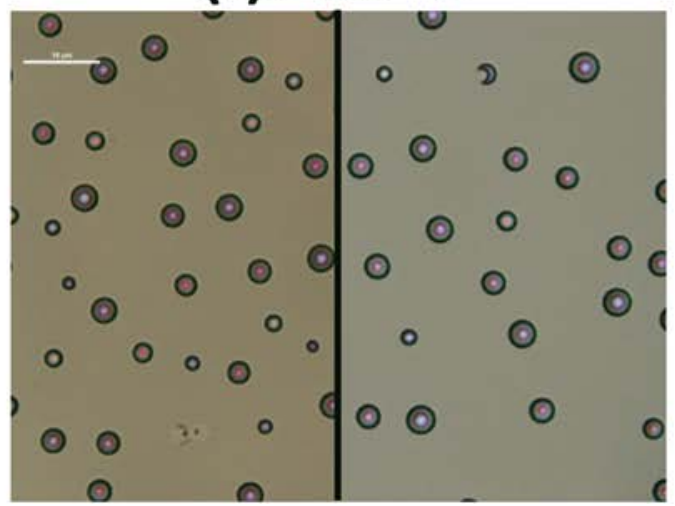

Figure 1: Optical microscopy (x100) images of samples after exposure at fixed temperatures for 5 hours to the flux from the capillary cracker at a $1 \mathrm{sccm} \mathrm{H}_{2}$ flow. The left-hand-side segment of each image represents an exposure to unmodified flux (ion+neutral); the righthand-side segments represent exposure with deflection of charged species (neutral-only). The 
A.S. Kuznetsov, M. A. Gleeson and F. Bijkerk (2014). "Temperature dependencies of hydrogen-induced blistering of thin film multilayers." Journal of Applied Physics 115(17): 173510.

DOI: $10.1063 / 1.4875484$

white scale bars represent $10 \mu \mathrm{m}$. 

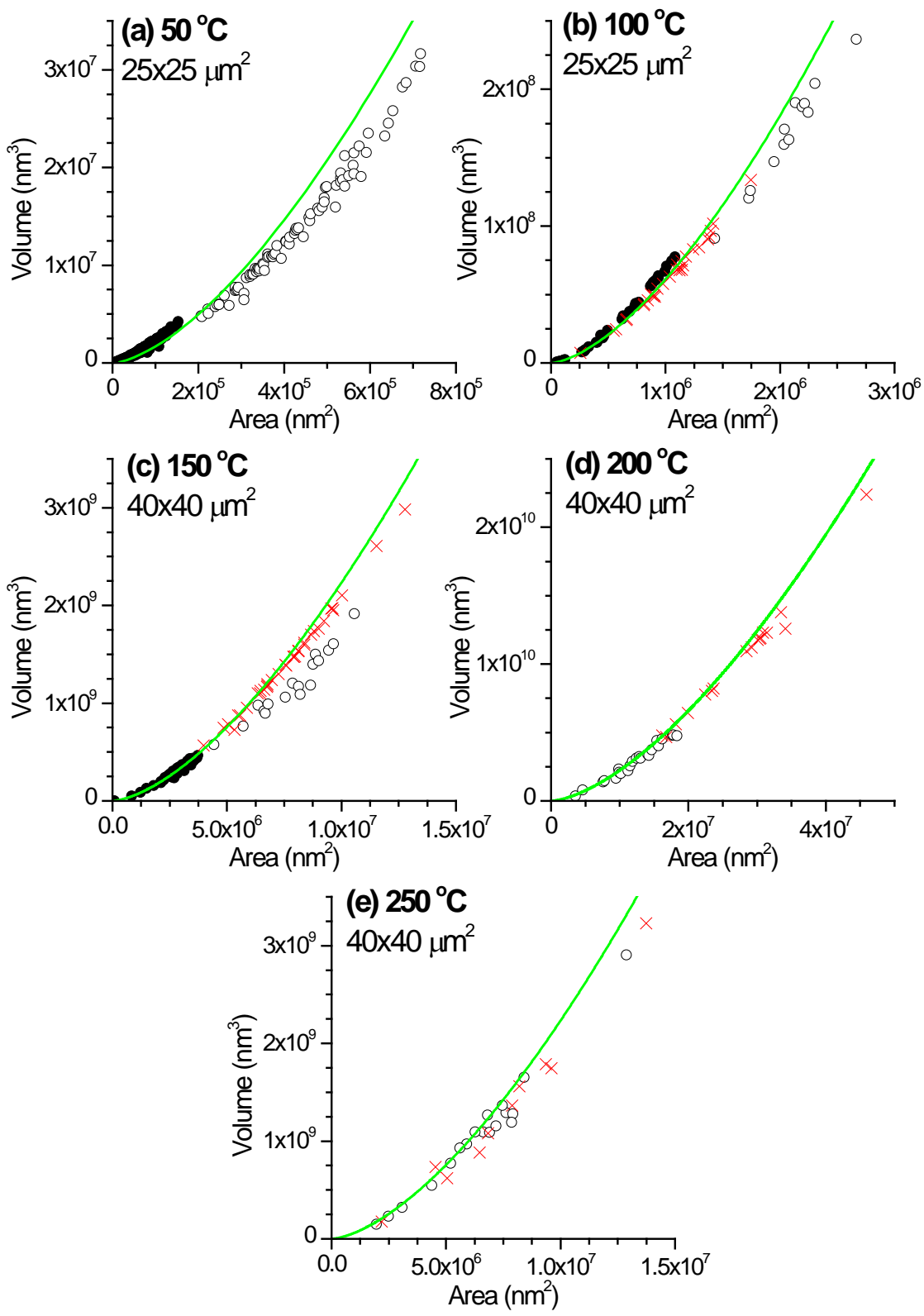

Figure 2: Plots of individual blister volume versus corresponding area covered derived from AFM scans of samples after exposure at fixed temperature. The panel labels indicate $\mathrm{T}_{\text {exposure }}$ and the scan area used for the analysis. Data from samples exposed to the ion+ neutral flux are represented by circles (filled and open indicate "ion-induced" and "thermal neutral" blisters, respectively). Data from samples exposed to the neutral-only flux are represented by crosses ("thermal neutral" blisters only). The solid line is a reference curve to aid comparison 
A.S. Kuznetsov, M. A. Gleeson and F. Bijkerk (2014). "Temperature dependencies of hydrogen-induced blistering of thin film multilayers." Journal of Applied Physics 115(17): 173510.

DOI: $10.1063 / 1.4875484$

between datasets. 


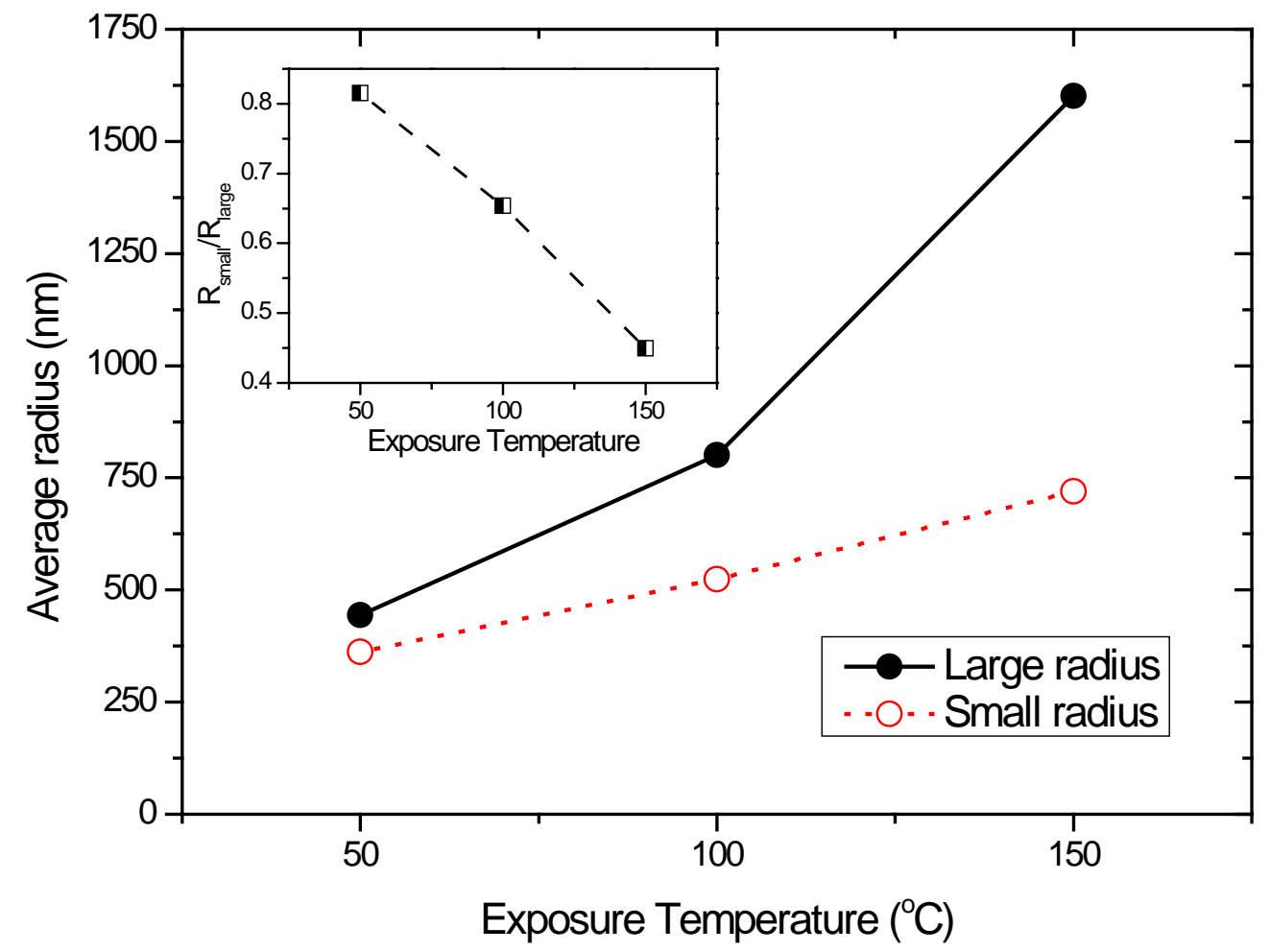

Figure 3: Plot of the radii of the large and small components of "double blister" features as a function of exposure temperature based on the averaged result of measurement from ten individual features. Inset: Ratio of the two radii. 


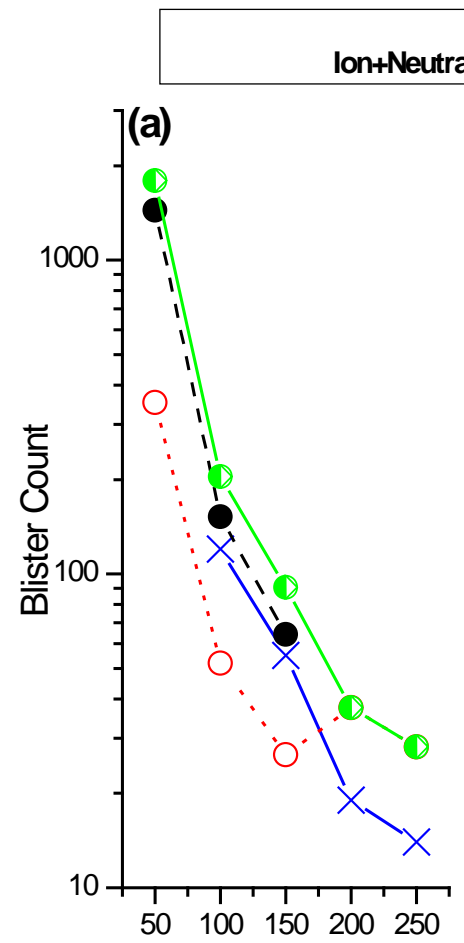

Neutral only: $-X-$
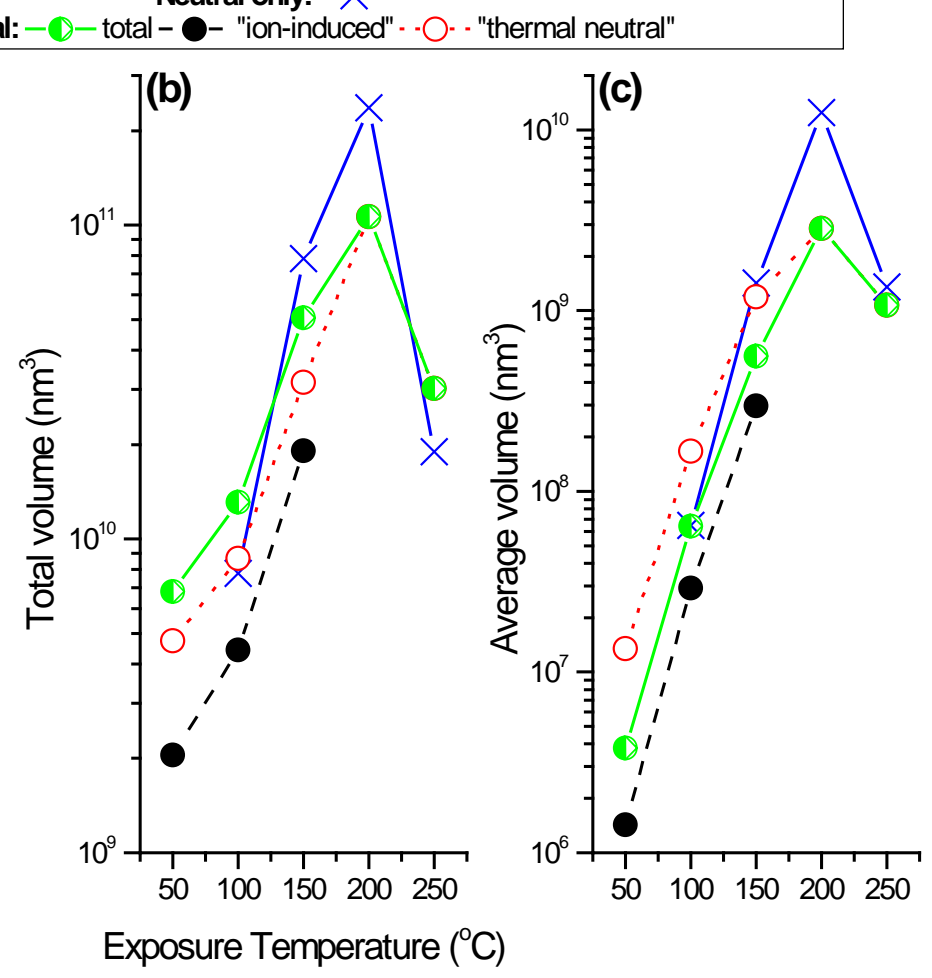

Figure 4: Plots of (a) blister count, (b) total occupied volume, and (c) average blister volume as a function of sample temperature during exposures to the ion+neutral and neutral-only fluxes. Data points are derived from the same AFM scans used to produce Figure 2. All values have been normalized to represent a $50 \times 50 \mu \mathrm{m}^{2}$ equivalent area. 

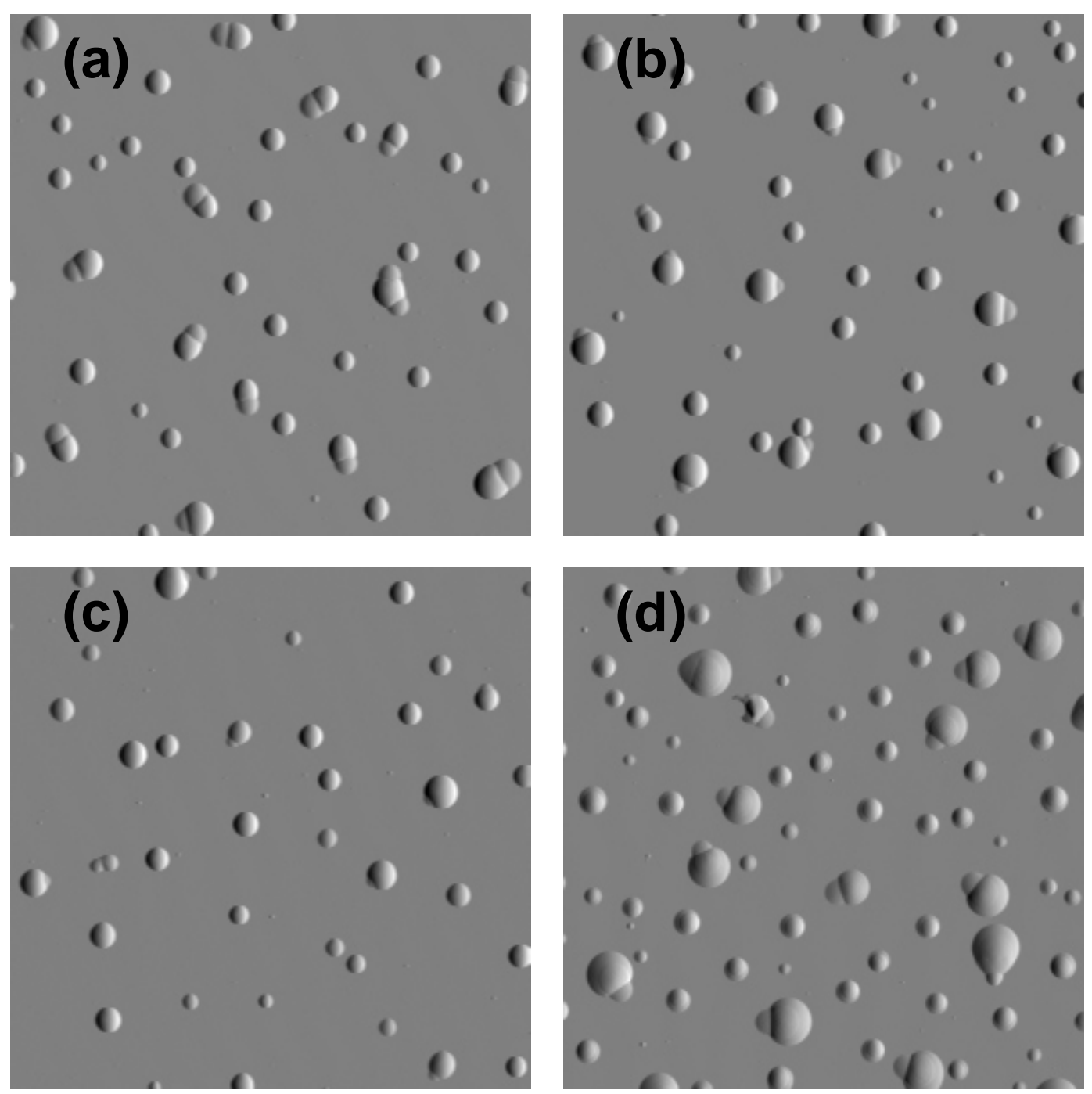

Figure 5: Shaded image representation of $20 \times 20 \mu \mathrm{m}^{2}$ AFM scans from samples after 5

hours of exposure to the ion + neutral flux at $100{ }^{\circ} \mathrm{C}$ with: (a) no pre-/post-annealing; (b) $200{ }^{\circ} \mathrm{C}$ pre-annealing; (c) $300{ }^{\circ} \mathrm{C}$ pre-annealing; and (d) $250{ }^{\circ} \mathrm{C}$ post-annealing. 

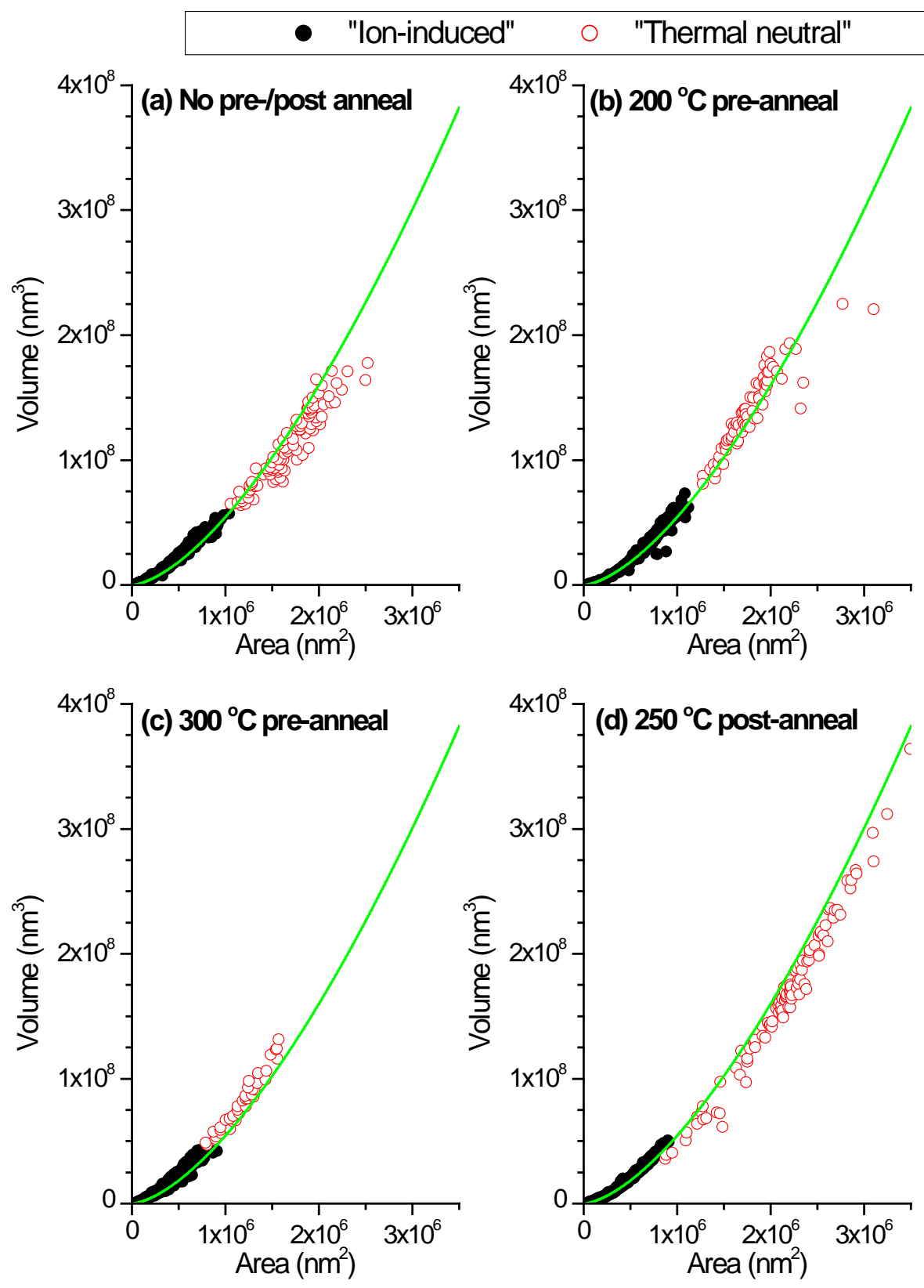

Figure 6: Volume versus area data of individual blisters derived from $50 \times 50 \mu \mathrm{m}^{2}$ AFM scans of samples after 5 hours of exposure to the ion+neutral flux at $\mathrm{T}_{\text {exposure }}=100{ }^{\circ} \mathrm{C}$. (a) No pre/post-annealing; (b) $200{ }^{\circ} \mathrm{C}$ pre-anneal; (c) $300{ }^{\circ} \mathrm{C}$ pre-anneal; and (d) $250{ }^{\circ} \mathrm{C}$ post-anneal.

"Ion-induced" and "thermal neutral" blisters are represented by filled and open circles, respectively. The reference curve from figure 2 is again reproduced. 
A.S. Kuznetsov, M. A. Gleeson and F. Bijkerk (2014). "Temperature dependencies of hydrogen-induced blistering of thin film multilayers." Journal of Applied Physics 115(17): 173510.

DOI: $10.1063 / 1.4875484$

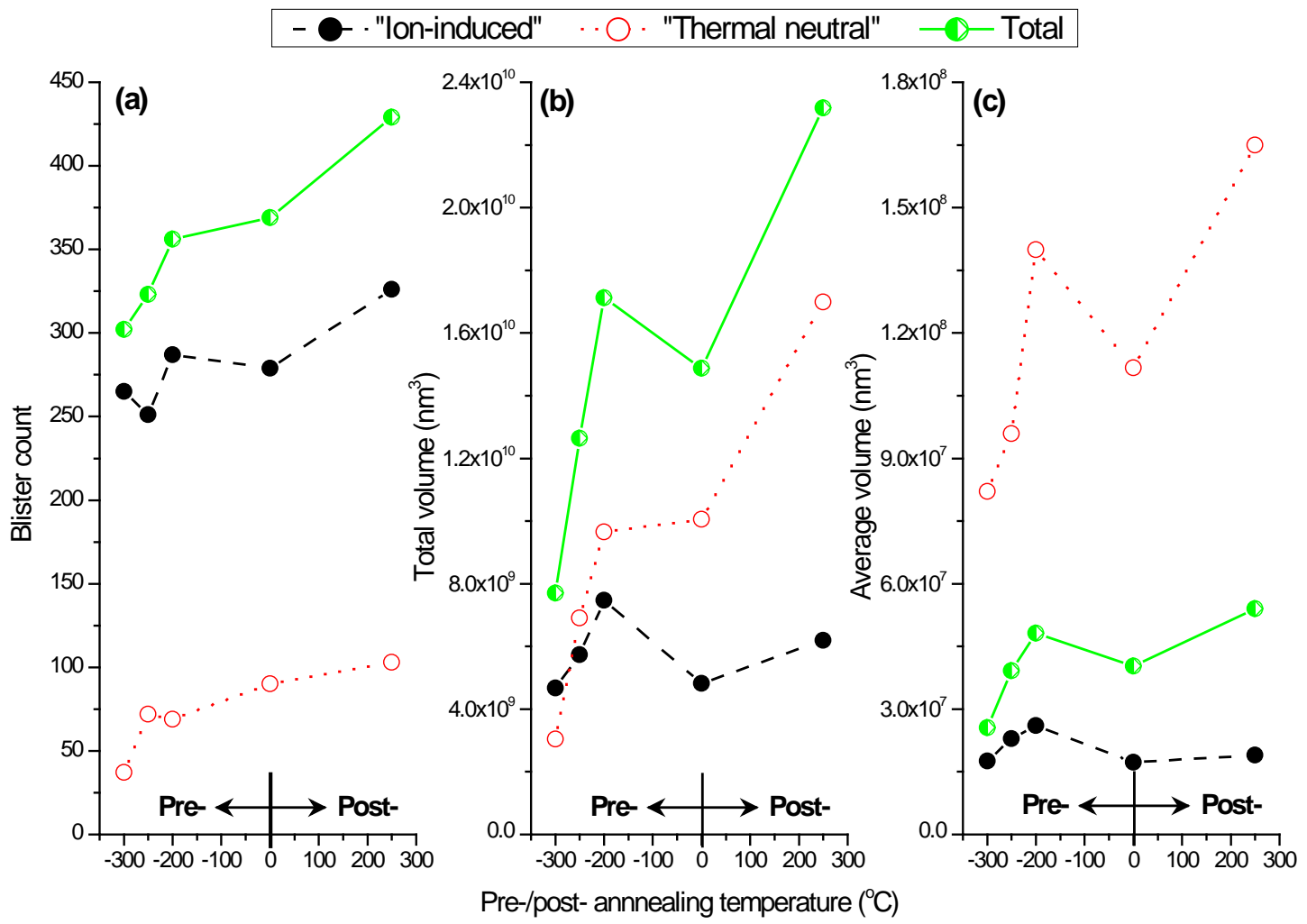

Figure 7: Plots of (a) the blister count, (b) the total volume occupied, and (c) the average blister volume after exposure to the ion+ neutral flux as a function of pre-/post-annealing temperature. Negative (positive) annealing temperatures signify pre- (post-)annealing. The data points are derived from analysis of 50x50 $\mu \mathrm{m}^{2}$ AFM scans. 

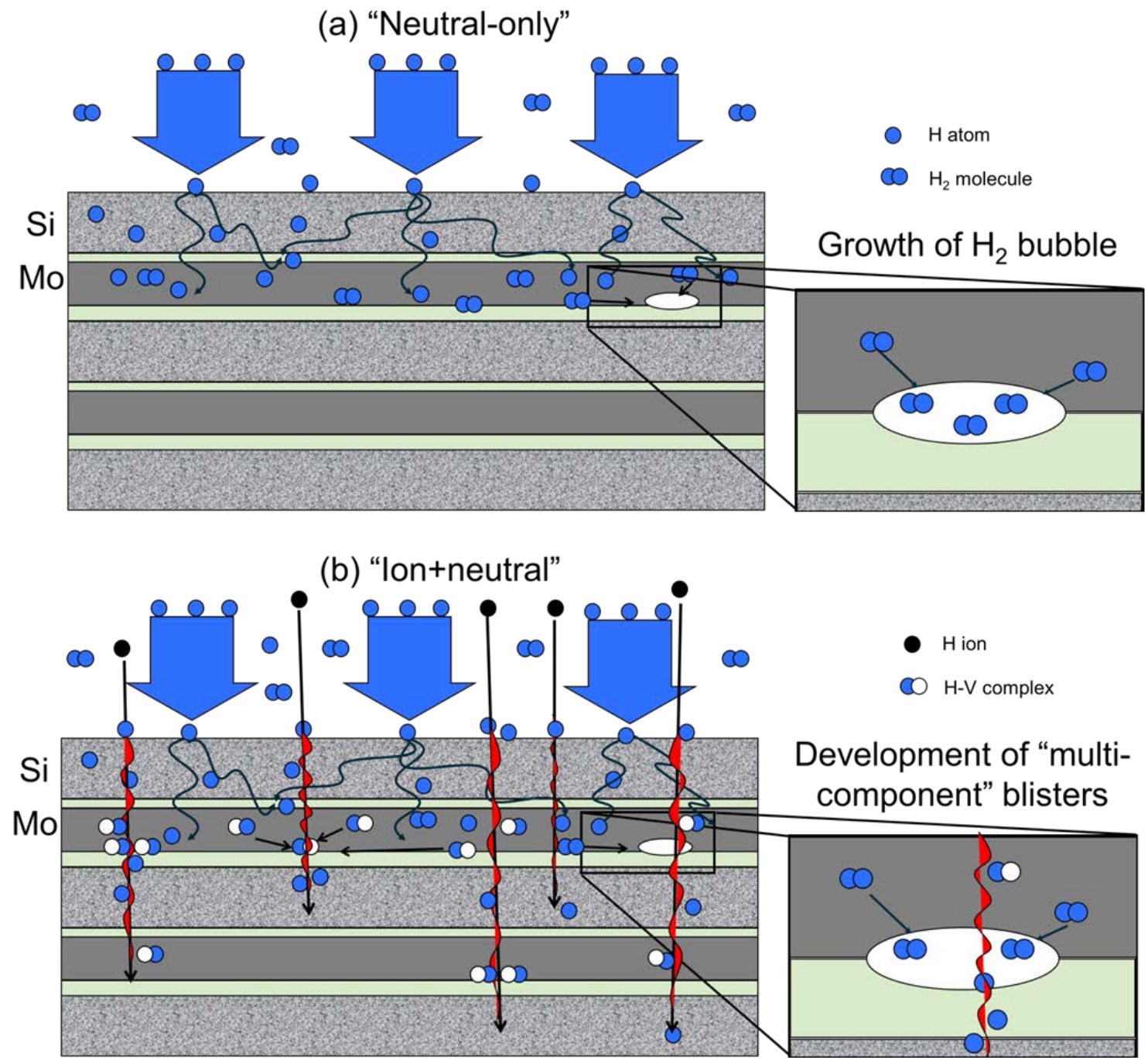

Figure 8: (a) Schematic representation of 'thermal neutral' process of hydrogen uptake and blister formation. (b) Schematic representation of 'ion-induced' H uptake and hydrogen transport to deeper layers. 